\title{
Erratum: Biotech patents still strong
}

\section{Stacey Lawrence}

Nat. Biotechnol. 25, 1341, 2007; published online December 2007; corrected after print 26 February 2008

In the version of this article initially published, the table listing the top 20 organizations with the most US biotech patents issued in 2006 is incorrect. Du Pont should be listed in sixth place, with 80 patents. The search of the USPTO database was done for "DuPont" rather than "Du Pont". The errors have been corrected in the HTML and PDF versions of the article.

Corrigendum: Toward the generation of rod and cone photoreceptors from mouse, monkey and human embryonic stem cells

Fumitaka Osakada, Hanako Ikeda, Michiko Mandai, Takafumi Wataya, Kiichi Watanabe, Nagahisa Yoshimura, Akiori Akaike, Yoshiki Sasai \& Masayo Takahashi

Nat. Biotechnol. 26, 215-224 (2008); published online 3 February 2008; corrected after print 26 February 2008

In the version of this article initially published, the author name Akiori Akaike should have been Akinori Akaike, and the density of ES cells and the composition of RA/T medium are incorrect. The errors have been corrected in the HTML and PDF versions of the article. 